\title{
Die Leere der Zeit, die Zeit der Leere
}

\author{
Enrico Danieli \\ Dr. med., Facharzt für Allgemeine Innere Medizin
}

Zwischen kurzer und langer Weile besteht ein Abgrund, eine Streckung der Zeit, Cioran (der grosse, rumänischfranzösische Aphoristiker [1911-1995], er setzt sich ein Leben lang mit l'inconvénient de l'être auseinander, ein Deserteur der Seele) spricht von einer ausgestrichenen Zeit. Ennui ist Daseinsleere, ist Trägheit der Seele, ist Unverbundenheit der Existenz, ist Überdruss. Langeweile ist die Tochter des Nichts. Sie ist aber auch Angst vor ihr, sie hemmt, provoziert Abwehr. Denn Langeweile (la noia) ist Unzufriedenheit, Verdriesslichkeit, ist: Nein-Sagen. - Heute nun ist in Mode das sogenannte Boreout-Syndrom; eine Umschreibung (Neudeutsch: ausgelangweilt) von Unterforderung am Arbeitsplatz aus dem Englischen boredom $=$ Langeweile - mit den Hauptsymptomen Desinteresse, Erschöpfung, Unterforderung, Langeweile: «Unterstress». Unbehandelt können Schlafstörungen, Antriebsstörungen, Depressionen die Folge sein, Ähnlichkeiten bestehen zum Burnout, eine Mischung aus herbeigeredetem Phänomen, Modeleid und beginnender Depression. Auffallend, dass wer die/seine Zeit nicht nutzt, diese als sinnlos zu erleben hat. So will es der Zeitgeist. Was ist sie denn, die lange Zeit? "Sie ist ein Gefühl, kaum ein Schmerz, empfunden eben, und dennoch spricht sie stets darein, und dennoch stört sie dich zu leben" (Th. Storm). Ja, Sie werden das Gefühl kennen, bei der x-ten Wiederholung der Empfehlungen zur Behandlung dieser Krankheit - ja, genau jetzt, Sie wiederholen sich, das ergibt sich so, das ist der Beruf, und doch wissen Sie, es wird nur wenig nützen. Natürlich haben Studien gezeigt ..., deshalb tun Sie es. Litaneienartig. Mit den Gedanken sind Sie nicht mit dabei, ihr Kopf entfernt sich. Unser Beruf ist nicht so, wie uns vorgebetet wird seit Jahr und Tag, vielseitig, spannend, abwechslungsvoll. Nein, manchmal ist sie einfach da, die Langeweile. Obwohl Sie mit ganzem Engagement dabei sind, sind Sie in Gedanken an einem anderen Ort, doch wo, könnten Sie nicht sagen, im Innern bleibt die Zeit stehen. So viel Aufwand haben Sie betrieben, um diesen Beruf zu erlernen, und nun das: ausserhalb von Raum und Zeit und auf rätselhafte Weise verbunden mit der Sub- stanzlosigkeit langer Stunden in der Kindheit: im Süden in der Kindheit der Siesta-Dämon Tag für Tag. Sich Ausruhen im wegen der Hitze verdunkelten Zimmer. Spiel-, Rede-, Bewegungsverbot. Ruhezeit. Das Fenster weit offen, corrente d'aria. Das Klappern des Rollladens. Zikaden. Glocken. Leere. Das Liegen im Bett, das Starren ins Dämmerlicht. Es ist zum ersten Mal, dass Fragen nach dem Was-Tun, nach dem Wozu-wasTun auftauchen. Später die Befreiung aus der Zimmerzelle - schlagartig, und alle Fragen scheinen sich im Nichts aufzulösen, um schon am nächsten Nachmittag zur Siestazeit bohrender denn je zurückzukehren. Noch ist es keine existentielle Langeweile, doch den Boden für diese tragen wir nun mit und in uns.

Medien, Sport, Mobilität, Politik, Medizin vereinen sich im Kampf gegen Langeweile, gegen Überdruss und Unzufriedenheit. Aktivismus, Unterhaltung, Lärm, power, geil, mega, surfen, chatten, mailen, mitmachen, mitschwimmen, mittanzen als Takt der Sinngebung eines verordneten Glücks. Erratisch mutet das befristete Zur-Ruhe-Kommen an mit Ausklinken, Abhängen, Abkühlen in Chill-out-Rooms, die Erholung von den immer weiter nach vorne peitschenden Elektrorhythmen; ob sie, die Ruhe, im tiefsten Innern nicht auch Langeweile beinhaltet? Langeweile: Sie ist ein zumeist einsamer Kampf gegen die Vorherrschaft der Zeit, des Zeitgeistes, sie gilt als Sünde, als Zeichen des Abseitsstehens. Verharren an Ort, Innehalten, Hinterfragen gelten als kontraproduktiv. Die Furcht vor diesem Jenseits lähmt, gilt es doch unter allen Umständen die acedia (Trägheit des Herzens) zu vermeiden. Nichts ist schlimmer als fehlendes Fortschreiten, fehlender Fortschritt. Vielleicht könnte ein Ausgleich zwischen vita activa und vita contemplativa helfen, eine Rhythmisierung des Alltags, ein abgewogener Wechsel zwischen Tätigkeit und Musse. Ein Vor, das auch dem Zurück Platz lässt. Vergessen wir nicht: Ohne Stillstand sind wir der Herrschaft der Zeit heillos ausgeliefert. Geben wir dem Taumel der Leere eine Chance! Stehen wir zur Langeweile - sie ist ein kleines Stück persönlicher Freiheit, der Freiheit, Nein zu sagen. 